\title{
Aboveground biomass production in an irrigation and fer- tilization field experiment with Eucalyptus globulus
}

\author{
C. Araújo ${ }^{1}$, J.S. Pereira², L. Leal ${ }^{1}$, M. Tomé2 ${ }^{2}$ J. Flower-Ellis ${ }^{3}$ and \\ T. Ericsson ${ }^{3}$ \\ 1 CELBI (Cellulose Beira Industrial), Figueira da Foz, Portugal, \\ 2 Instituto Superior de Agronomia, Dept. of Forestry, P-1399 Lisbon, Portugal, and \\ 3 Swedish University of Agriculture Sciences, Uppsala, Sweden
}

\section{Introduction}

For a given climate, optimal growth rates may be achieved if mineral nutrient additions are scheduled to meet the needs of the plants determined by their relative growth rate (Ingestad, 1988). To assess optimum biomass production of Eucalyptus globulus in Portugal and to study the physiological mechanisms of the response to the addition of nutrients and water, a field experiment was established in March 1986 (Pereira et al., 1988). In this paper, we present the results of aboveground biomass production and partitioning for the 1st 2 yr of growth.

\section{Materials and Methods}

Planting took place in March of 1986 at a spacing of $3 \times 3 \mathrm{~m}$. At planting, each seedling received $200 \mathrm{~g}$ of NPK fertilizer containing $14 \mathrm{~g} \mathrm{~N}$, $18.3 \mathrm{~g} \mathrm{P}$ and $11.6 \mathrm{~g} \mathrm{~K}$. The experimental design consisted of 3 treatments and a rainfed control (C). 1) F - solid fertilization applied twice per growing season (in spring and autumn) to rainfed plots. The fertilization consisted of a broadcast fertilizer, with the proportions $100 \mathrm{~N}: 88 \mathrm{~K}$ :
$32 \mathrm{P}$ plus micronutrients. Fertilizers containing $90 \mathrm{~kg} / \mathrm{ha}$ and $1150 \mathrm{~kg} / \mathrm{ha}$ of $\mathrm{N}$ were applied in 1986 and 1987, respectively. 2) I - water supplied daily from April through October, through drip tubes. In 1986 and 1987, 611 and $629 \mathrm{~mm}$ of water were supplied by irrigation in addition to 645 and $905 \mathrm{rnm}$ of rainfall in 1986 and 1987 , respectively. 3) IL - irrigation as in I plus a complete liquid fertilizer, with micronutrients, applied once per week according to the needs of the plants estimated by the relative growth rate. The total fertilizer supplied was, in $\mathrm{kg} / \mathrm{ha}$, $60 \mathrm{~N}, 46 \mathrm{~K}$ and $26 \mathrm{P}$ in 1986 and $160 \mathrm{~N}, 123 \mathrm{~K}$ and $69 P$ in 1987. Each treatment was applied to 2 plots with an area of 0.30 ha each, leaving 2 protection rows between plots.

Twelve trees per treatment were harvested for biomass studies in September of 1986 and February of 1987. In February of 1988, 10 trees per treatment were selected for the same purpose. Biomass components were separated and a subsample of each component was ovendried at $80^{\circ} \mathrm{C}$ to evaluate the dry weight to fresh weight ratio and estimate biomass.

\section{Results}

As shown in Table I, the treatments strongly affected growth especially in the irrigated treatments (IL and I). During the first $6 \mathrm{mo}$, the effect of $F$ was negligible, 
as compared to the control (C), whereas, in $\mathrm{L}$ and $\mathrm{I}$, the aboveground biomass was 262 and $185 \%$ greater than in C. That was a period when water stress occurred in the rainfed plots ( $F$ and $C$ ). During the following rainy season (September 1986February 1987) and during the 2nd yr of growth, there was a significant increase in the biomass of the F plots. In all cases, IL and $I$ resulted in higher biomass accumulation rates than the rainfed treatments. The annual biomass production accumulated during the period until canopy closure was linearly related to the leaf area index $L A I$ (Fig. 1). The fastest growing trees (IL) had reached a high $L A /$ by February 1988 $(L A I=4.1)$. The proportion of each biomass component changed with treatments (Table II). Leaves represented a greater percentage of total biomass in the rainfed treatments ( $F$ and $C$ ) than in $I L$ and $I$. The accumulation of stem biomass was greater in $\mathrm{IL}$ and $\mathrm{I}$ than in $\mathrm{F}$ and $\mathrm{C}$, both in absolute amounts and in relation to the amount of foliage biomass (see Table II). Most of the variation in stem biomass resulted from wood accumulation, since bark varied only between 6 and $9 \%$, approximately.

\section{Discussion}

The supply of water and mineral nutrients according to plant needs had the greatest

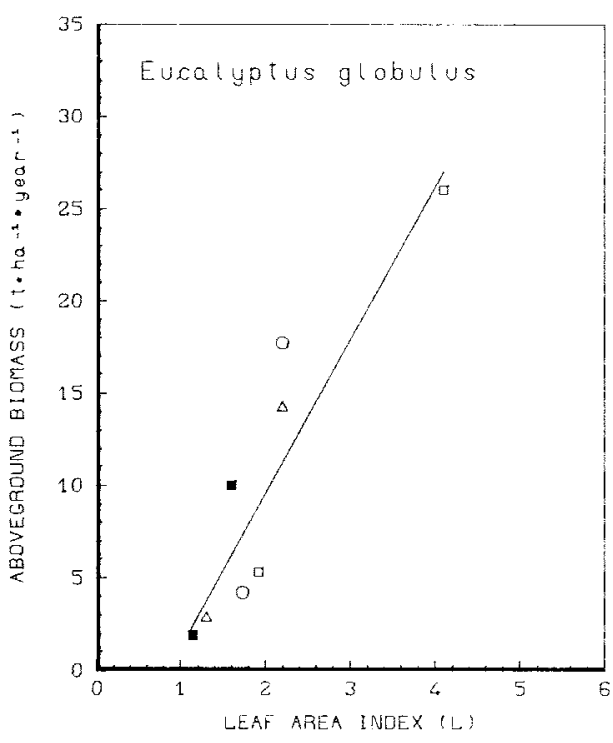

Fig. 1. Relationship between aboveground biomass productivity and leaf area index $(L A I)$ for Eucalyptus globulus trees 11 and 23 mo after plantation: $\square \mathrm{IL}$; $\mathrm{O}: \mathrm{I} ; \Delta: \mathrm{F}$ and $\mathbf{E}: \mathrm{C}$. Regression line: productivity $=-6.97 \times 8.29(L A I) ; R^{2}=0.88$.

effect on biomass production in comparison with irrigation or fertilization alone, as had been suggested by Ingestad (1988). An abundant water supply in the summer (I) ranked second in promoting biomass accumulation, suggesting that water deficits play a major role in decreasing production under these climatic conditions.

Table I. Average standing aboveground biomass (tha) in February 1987 and February 1988, when the seedlings were 11 and 23 months old, respectively.

\begin{tabular}{lll}
\hline Treatment & \multicolumn{2}{l}{ Standing aboveground biomass (tha) } \\
\cline { 2 - 3 } & Feb. 1987 & Feb. 1988 \\
\hline IL & 5.31 & 28.4 \\
I & 4.20 & 17.3 \\
F & 2.78 & 15.2 \\
C & 1.90 & 10.7 \\
\hline
\end{tabular}


Table II. Biomass partition among the aboveground components in September 1986 and in February 1987 and 1988, (fraction of total) and stem biomass accumulated per unit of leaf biomass.

\begin{tabular}{lllll}
\hline Treatments & Stem & Branches & Leaves & Stem/leaf biomass \\
\hline Sept. 1986 & & & & \\
IL & 0.318 & 0.245 & 0.438 & 0.7 \\
I & 0.284 & 0.238 & 0.478 & 0.6 \\
F & 0.237 & 0.215 & 0.551 & 0.4 \\
C & 0.260 & 0.200 & 0.540 & 0.5 \\
Feb. 1987 & & & & \\
IL & 0.451 & 0.216 & 0.336 & 1.4 \\
I & 0.414 & 0.208 & 0.382 & 1.1 \\
F & 0.348 & 0.227 & 0.429 & 0.8 \\
C & 0.343 & 0.202 & 0.457 & 0.8 \\
Feb. 1988 & & & & \\
IL & 0.672 & 0.161 & 0.166 & 4.0 \\
I & 0.659 & 0.153 & 0.188 & 3.5 \\
F & 0.583 & 0.203 & 0.214 & 2.7 \\
C & 0.602 & 0.173 & 0.225 & 2.7 \\
\hline
\end{tabular}

One of the major effects of the treatments was to increase leaf production in relation to the control and biomass production was strictly related to $L A /$ until canopy closure. The photosynthetic capacity of each individual leaf did not increase significantly with fertilization and irrigation (unpublished data). This also suggests that models based upon a simple relationship between biomass production and light interception by the foliage (a function of $L A I$ ) may be applied over a range of environmental situations for young eucalypt plantations (McMurtrie et al., 1988). Irrigation alone or with fertilization resulted in larger plants with a greater percentage of stem in relation to total and foliage biomass than in the rainfed plots. It is likely that, in the absence of irrigation, more biomass was allocated to roots than to stem, as suggested by Cannell (1985).

\section{References}

Cannell M.G.R. (1985) Dry matter partitioning in tree crops. In: Trees as Crop Plants. (Cannell M.G.R. \& Jackson J.E., eds.), Institute for Terrestrial Ecology, Monks Wood, Huntingdon, U.K. pp. 160-19:3

Ingestad T. (198:8) New concepts on soil fertility and plant nutrition as illustrated by research on forest trees and stands. Geoderma 40, 237-252

MCMurtrie R.E., Landsberg J.J. \& Linder S. (1989) Research priorities in field experiments on fast-growing tree plantations: implications of a mathematical production model. In: Biomass Production by Fast-Growing Trees. (Pereira J.S. \& Landsberg J.J., eds.), Kluwer, Dordrecht, pp. 181-207

Pereira J.S., Linder S., Araújo M.C., Pereira H., Ericsson T., Borralho N. \& Leal L. (1988) Optimization of biomass production in Eucalyptus globulus plantations - a case study. In: Biomass Production by Fast-Growing Trees. (Pereira J.S. \& Landsberg J.J., eds.), Kluwer, Dordrecht pp. 101-121 